\title{
A comparison of the accuracy of fetal MRI and prenatal ultrasonography at predicting lesion level and perinatal motor outcome in patients with myelomeningocele
}

\author{
Brandon A. Sherrod, MD, ${ }^{1}$ Winson S. Ho, MD, ${ }^{1}$ Alec Hedlund, BS, ${ }^{1}$ Anne Kennedy, MBBCh, ${ }^{2}$ \\ Betsy Ostrander, MD, ${ }^{3}$ and Robert J. Bollo, MD ${ }^{1}$
}

'Department of Neurosurgery, Division of Pediatric Neurosurgery, University of Utah, Primary Children's Hospital; ${ }^{2}$ Department of Radiology, Division of Clinical Radiology, University of Utah; and 'Department of Pediatrics, Division of Pediatric Neurology, University of Utah, Primary Children's Hospital, Salt Lake City, Utah

\begin{abstract}
OBJECTIVE Prenatal imaging has several critical roles in the diagnosis and management of myelomeningocele, including specific family counseling and the selection of fetal surgery or postnatal repair. In this study, the authors compared the accuracy of fetal MRI and prenatal ultrasonography (US) in predicting the spinal lesion level and assessed the correlation between imaging findings and motor function as independently evaluated by a physical therapist (PT) after birth.

METHODS A retrospective review of demographic and clinical data was performed to identify children who had been treated with postnatal myelomeningocele closure at a single institution between March 2013 and December 2018. Patients were eligible for inclusion if they had all of the following: prenatal US identifying the neural tube defect level, fetal MRI identifying the neural tube defect level, and postoperative PT evaluation identifying the motor deficit level. Statistical analysis was performed using Cohen's kappa coefficient to compare the US- and MRI-demonstrated lesion level and correlate these findings with the motor level assigned postnatally by a PT via manual muscle testing.
\end{abstract}

RESULTS Thirty-four patients met the inclusion criteria. The mean gestational age at US was $23.0 \pm 4.7$ weeks, whereas the mean gestational age at MRI was $24.0 \pm 4.1$ weeks. The mean time from surgery to the PT evaluation was $2.9 \pm$ 1.9 days. Prenatal US and MRI were in agreement within one spinal level in $74 \%$ of cases $(25 / 34, \kappa=0.43)$. When comparing the US-demonstrated spinal level with the PT-assigned motor level, the two were in agreement within one level in $65 \%$ of cases $(22 / 34, \kappa=0.40)$. When comparing MRI-demonstrated spinal level with the PT motor level, the two were in agreement within one level in $59 \%$ of cases $(20 / 34, \kappa=0.37)$. MRI and US were within two spinal levels of the PT evaluation in $79.4 \%$ and $85.3 \%$ of cases, respectively. MRI and US agreed within two levels in $97.1 \%$ of cases. Prenatal US and MRI were equivalent when comparing the difference between the imaged level and the postnatal motor deficit level (mean level difference: $1.12 \pm 1.16$ vs $1.17 \pm 1.11, p=0.86$ ).

CONCLUSIONS Prenatal US and MRI equivalently predicted the postnatal motor deficit level in children with myelomeningocele. These data may be valuable in prenatal prognostication.

https://thejns.org/doi/abs/10.3171/2019.7.FOCUS19450

KEYWORDS myelomeningocele; spina bifida; ultrasound; magnetic resonance imaging; physical therapy

$\mathrm{M}$ YELOMENINGOCELE is the most common neural tube defect and congenital anomaly of the central nervous system, affecting approximately 1 neonate in 1000 live births worldwide. ${ }^{10,15}$ In the United States, approximately 2 neonates in every 10,000 live births will undergo surgical closure of a myelomeningocele. ${ }^{14}$ Prenatal imaging evaluation is essential in early diagnosis to accurately counsel families regarding the potential benefits of different treatment options, including fetal repair.
One component of the decision to pursue fetal surgery is understanding how this decision may impact functional outcome elements such as ambulation given the slight improvement in neurological function that fetal intervention may confer. ${ }^{2}$

For decades, prenatal transabdominal ultrasonography (US) has been the modality of choice for prenatal diagnosis of neural tube defects such as myelomeningocele, as well as other abnormalities of the central nervous sys-

ABBREVIATIONS IMSG = International Myelodysplasia Study Group; PT = physical therapist; US = ultrasonography .

SUBMITTED May 31, 2019. ACCEPTED July 16, 2019.

INCLUDE WHEN CITING DOI: 10.3171/2019.7.FOCUS19450. 
tem. ${ }^{6,8}$ More recently, fetal MRI has been used in conjunction with screening US for further prenatal evaluation of myelomeningocele. 9,13,18,20,21 Both US and MRI have demonstrated validity in terms of prenatal imaging correlation with postnatal imaging, with previous reports of approximately $60 \%-90 \%$ prenatal-postnatal imaging agreement. ${ }^{1,6,8,13}$ Prior studies have also correlated prenatal US and MRI in terms of prenatal neural tube defect level and lateral ventricle measurements in patients with myelomeningocele, finding good agreement overall. . $^{1,3,4,12,13,19}$

To our knowledge, no study has specifically investigated the relationship between prenatal imaging and postnatal motor deficit in infants with myelomeningocele, particularly by using formal manual muscle testing performed by a physical therapist (PT). Understanding the degree of correlation between prenatal imaging and postnatal deficit would provide helpful information regarding deficit prognosis by using prenatal imaging. The goal of the current study was to evaluate the diagnostic and prognostic ability of prenatal US and MRI as they relate to postnatal motor deficit in myelomeningocele to aid in accurate and patientspecific prenatal counseling.

\section{Methods \\ Patient Cohort}

Institutional review board approval was granted for the study before data collection. We performed a retrospective chart review to identify children who had been treated with postnatal myelomeningocele closure in the period from March 2013 through December 2018 at Primary Children's Hospital. Patients were eligible for inclusion if they had all of the following: prenatal transabdominal US study with the corresponding spinal lesion level identified, fetal MRI study with the corresponding spinal lesion level identified, and postoperative manual muscle testing by a PT with an assigned motor level. Patients were excluded if their imaging reports were not available (with read and lesion level determination by radiology faculty at our institution), if they had been treated with fetal surgery, or if they had not undergone a documented postoperative PT evaluation within 1 week of myelomeningocele repair.

\section{Imaging Modalities}

Prenatal images were obtained solely to assess the anatomical level of the neural tube defect. Transabdominal US was the initial imaging modality for all included patients. We did not include patients in the current study if they did not have a reviewable US study before prenatal MRI. The specific ultrasound imaging equipment and technique varied by the site of imaging (ultrasound images were acquired at the University of Utah Hospital, Primary Children's Hospital, or a referring satellite clinic), but the first screening US study that was available for each patient with a diagnosis of a neural tube defect and an assigned spinal level was used for study purposes. Fetal MRI was reviewed once it had been confirmed that the patient had a prior screening US with mention of a spinal defect. All MRI was performed on a Siemens Avanto 1.5-T scanner (Siemens Medical). All images were interpreted by an attending radiologist with expertise in fetal MRI. Figure 1 displays representative fetal MRI and prenatal US studies.
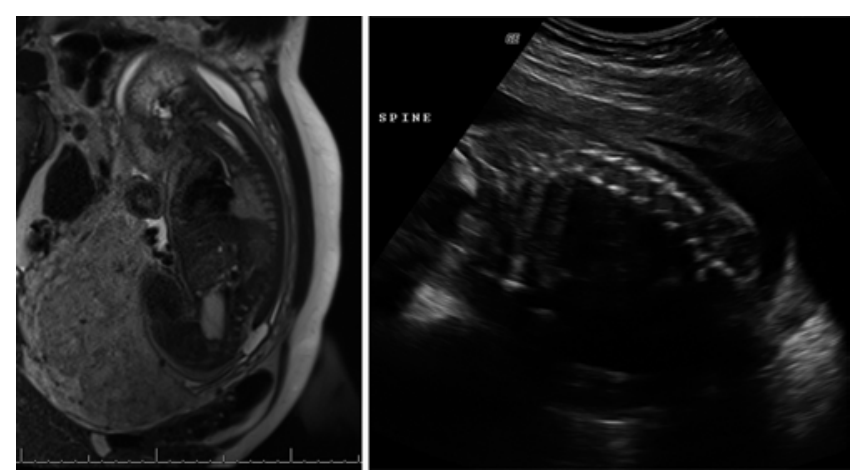

FIG. 1. Representative fetal MRI (left) and prenatal US (right) studies of the same fetus demonstrating an open neural tube defect at approximately the L4 level.

\section{Physical Therapy Evaluation}

Study inclusion criteria required each patient to have a postnatal, postoperative (post-myelomeningocele closure) PT evaluation, including full manual muscle testing by a licensed PT in the inpatient setting within 1 week of surgery. Evaluations were performed by different PTs, but they all followed established guidelines specified by the International Myelodysplasia Study Group (IMSG) criteria for assigning motor levels (Table 1). ${ }^{16,23}$ The examination must have documented motor evaluation of the hip flexors/extensors, knee flexion/extension, and plantar flexion/ dorsiflexion with corresponding assessment of functional motor level.

\section{Statistical Analysis}

Descriptive statistics including frequencies of all variables of interest were generated. Contingency tables were generated, and Cohen's kappa ( $\kappa)$ coefficient was calculated to correlate the US-demonstrated lesion level with the MRI-demonstrated lesion level and to correlate the postnatal PT-assigned motor level with the prenatal US and MRI spinal levels. The percent agreement within one level between the imaging modalities (US and MRI) was calculated, as was the percent agreement within one level between imaging modalities and the PT motor level. Comparisons were also made for agreement within two levels. A $\kappa$ value of $0-0.4$ indicates marginal agreement; $0.41-0.75$, good agreement; and 0.76-1.00, excellent agreement. The absolute difference in spinal level between modalities was calculated. Continuous variables were compared using the unpaired Student t-test with a two-tailed $\mathrm{p}$ value. Continuous variables were reported as the mean \pm standard deviation unless otherwise specified. The alpha for significance was set to 0.05 . All statistical analyses were performed using IBM SPSS software version 25 (IBM Corp.).

\section{Results}

Thirty-four patients treated with postnatal myelomeningocele closure met the inclusion criteria (Table 2). There was a slight female predominance to our cohort $(\mathrm{n}=19$ [55.9\%]). The mean gestational age at the time of US was $23.0 \pm 4.7$ weeks, whereas the mean gestational age at MRI was $24.0 \pm 4.1$ weeks. All patients were treated with postnatal myelomeningocele closure. The mean time from 
TABLE 1. IMSG criteria for motor function evaluation in children with myelomeningocele

\begin{tabular}{cc}
\hline $\begin{array}{c}\text { Motor } \\
\text { Level }\end{array}$ & \multicolumn{1}{c}{$\begin{array}{c}\text { Functional Assessment by Muscle Group } \\
(\geq \text { grade } 3 \text { strength) }\end{array}$} \\
\hline T10 & $\begin{array}{c}\text { Weak lower trunk musculature, no observable lower extremity } \\
\text { movement }\end{array}$ \\
\hline T12 & $\begin{array}{c}\text { Quadratus lumborum (lat vertebral column flexion), no ob- } \\
\text { servable lower extremity movement }\end{array}$ \\
\hline L2 & Hip flexion, hip adduction \\
\hline L3 & Hip flexion, knee extension \\
\hline L4 & Knee extension, ankle dorsiflexion, ankle inversion \\
\hline L5 & $\begin{array}{c}\text { Ankle dorsiflexion \& inversion, knee flexion, stronger ankle } \\
\text { plantar flexion w/ inversion (peroneus tertius) }\end{array}$ \\
\hline S1 & $\begin{array}{c}\text { At least 2 of the following: plantar flexion, gluteus medius } \\
\text { muscle, gluteus maximus muscle, hip stability }\end{array}$ \\
\hline S2-3 & $\begin{array}{c}\text { All lower trunk \& lower extremity muscle groups grade 5 } \\
\text { (exception for 1 or 2 groups w/ grade 4 strength) }\end{array}$ \\
\hline
\end{tabular}

Based on material from McDonald et al., ${ }^{17}$ Cameron and Monroe, ${ }^{7}$ and Frontera et al. ${ }^{11}$

${ }^{*}$ Grade 3 = antigravity.

birth to surgery was $1.0 \pm 0.5$ days, and the mean time from surgery to PT evaluation was $2.9 \pm 1.9$ days.

Table 3 displays the anatomical distribution of the spinal defect and motor deficit level by imaging modality and PT evaluation. Figure 2 displays the relative difference in spinal level by modality. The majority of spinal defects on prenatal imaging had the upper spinal level in the lower lumbar area $(70.6 \%$ and $79.4 \%$ of defects were at or below L4 for US and MRI, respectively). Half (50.0\%) of the motor deficit level distribution on PT evaluation was at or below L4. However, there were more upper lumbar deficits on PT evaluation (8 patients [23.5\%] with L1 or L2 level) compared with those on US (1 patient [2.9\%]) and MRI (no patients). Very few thoracic lesions (1 each [2.9\%] on MRI and PT evaluation) were observed.

Table 4 displays the imaging modality analysis. Prenatal US and MRI were in agreement within one spinal level in $74 \%$ of cases $(25 / 34, \kappa=0.43)$ and within two levels of each other in $97.1 \%$ of cases. The mean difference in spinal level between the two modalities was $0.77 \pm 0.87$ levels. When comparing US spinal level with PT motor deficit level, the two were in agreement within one level in $65 \%$ of cases $(22 / 34, \kappa=0.40)$. When comparing MRI spinal level with PT motor level, the two were in agreement within one level in $59 \%$ of cases $(20 / 34, \kappa=0.37)$. US and MRI levels were within two levels of the PT evaluation in $85.3 \%$ and $79.4 \%$ of cases, respectively. None of these comparisons was significantly different $(\mathrm{p}>0.05)$. Prenatal US and MRI were equivalent when comparing the difference between the imaged level and the PT motor level (mean difference in level: $1.12 \pm 1.16$ vs $1.17 \pm 1.11$, $\mathrm{p}=0.86)$.

\section{Discussion}

To our knowledge, this is the first study to report an association between prenatal imaging modalities and post-
TABLE 2. General characteristics of patients treated with postnatal myelomeningocele closure

\begin{tabular}{lr}
\hline \multicolumn{1}{c}{ Variable } & Value \\
\hline Total no. of patients & $34(100 \%)$ \\
\hline Sex & $15(44.1 \%)$ \\
\hline M & $19(55.9 \%)$ \\
\hline F & $23.0 \pm 4.7$ \\
\hline Gestational age at US in wks & $24.0 \pm 4.1$ \\
\hline Time from surgery to PT evaluation in days & $2.9 \pm 1.9$ \\
\hline Postnatal closure & $34(100 \%)$ \\
\hline Time from birth to surgery in days & $1.0 \pm 0.5$ \\
\hline
\end{tabular}

Values are expressed as number (\%) or as mean \pm standard deviation.

natal motor deficit by formal PT evaluation according to established criteria. Prenatal imaging has served a vital role in the diagnosis and management of myelomeningocele; however, whether prenatal imaging can reliably predict postnatal motor function remains unclear. We have shown that prenatal US and MRI are equally effective in predicting postnatal motor deficit level and are generally within one level of the postnatally observed motor deficit. Furthermore, in agreement with a small number of prior studies, ${ }^{1,13}$ we have demonstrated that US and MRI have good interstudy agreement regarding spinal defect level.

In our patient cohort, prenatal MRI and prenatal US agreed within one spinal level in $74 \%$ of cases with a $\mathrm{K}$ of 0.43 , indicating good agreement. Furthermore, the absolute difference between US and MRI was $0.77 \pm 0.87$ levels (mean \pm standard deviation). Overall, these findings are consistent with those in prior studies. Aaronson et al. ${ }^{1}$ compared prenatal US and prenatal MRI with postnatal spinal radiographs in patients with myelomeningocele, finding that $79 \%$ of 70 prenatal US images correlated within one level of postnatal spinal radiographs $(\kappa=0.60)$ and that $82 \%$ of 38 prenatal MRI studies correlated within one level of postnatal radiographs $(\kappa=0.63)$; these authors did not report a statistical comparison of US and MRI.

TABLE 3. Anatomical distribution of spinal defect or motor deficit level by modality

\begin{tabular}{lccc}
\hline & \multicolumn{3}{c}{ No. (\%) } \\
\cline { 2 - 4 } $\begin{array}{c}\text { Upper Spinal } \\
\text { Level }\end{array}$ & $\begin{array}{c}\text { Prenatal US } \\
\text { Spinal Defect } \\
\text { Level }\end{array}$ & $\begin{array}{c}\text { Prenatal MRI } \\
\text { Spinal Defect } \\
\text { Level }\end{array}$ & $\begin{array}{c}\text { Postnatal PT } \\
\text { Motor Deficit } \\
\text { Level }\end{array}$ \\
\hline Above T12 & $0(0)$ & $0(0)$ & $0(0)$ \\
\hline T12 & $0(0)$ & $1(2.9)$ & $1(2.9)$ \\
\hline L1 & $0(0)$ & $0(0)$ & $5(14.7)$ \\
\hline L2 & $1(2.9)$ & $0(0)$ & $3(8.8)$ \\
\hline L3 & $9(26.5)$ & $6(17.6)$ & $8(23.5)$ \\
\hline L4 & $5(14.7)$ & $7(20.6)$ & $7(20.6)$ \\
\hline L5 & $10(29.4)$ & $11(32.4)$ & $4(11.8)$ \\
\hline S1 & $9(26.5)$ & $7(20.6)$ & $6(17.6)$ \\
\hline S2 or below & $0(0)$ & $2(5.9)$ & $0(0)$ \\
\hline
\end{tabular}




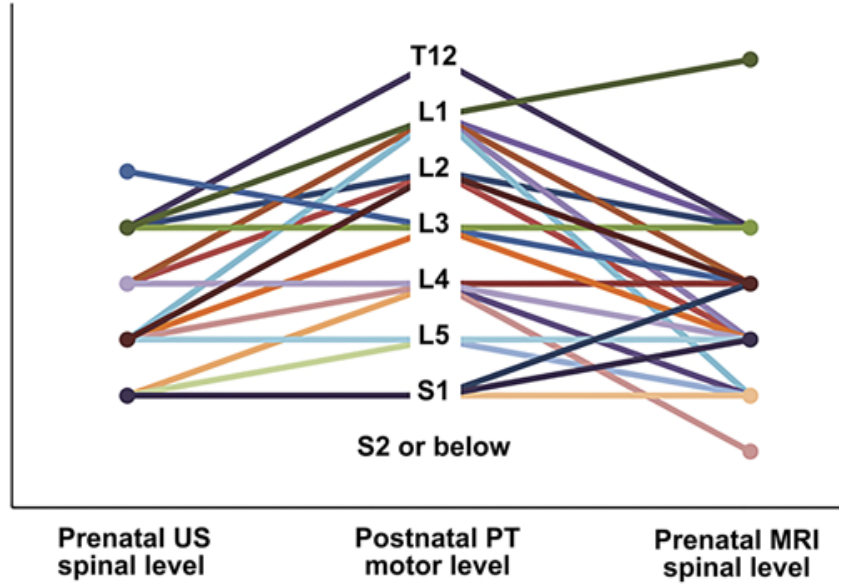

FIG. 2. Relative difference in spinal level by modality (in reference to postnatal PT motor level). Each color represents one patient.

Carreras et al. ${ }^{8}$ published a comparison of prenatal US and postnatal neurological examination in 18 infants with myelomeningocele; they found that agreement between prenatal US and postnatal segmental levels on examination was $91.7 \%$ for the right limb $(\kappa=0.80)$ and $88.9 \%$ for the left limb $(\kappa=0.73)$. Griffiths et al. ${ }^{13}$ reported on agreement between fetal MRI and US with regard to general spinal deformity, finding in $40(80 \%)$ of 50 fetuses that MRI and US were in complete agreement. Bruner et al. ${ }^{6}$ described a comparison of community prenatal US imaging findings with postnatal radiographs. They demonstrated that community-assigned levels agreed perfectly with postdelivery levels in $26 \%$ of cases, whereas $66 \%$ agreed within one level and $80 \%$ agreed within two levels. Collectively, these data suggest that prenatal US and MRI are equivalent overall in their ability to localize open neural tube defects.

Prior studies have investigated the utility of prenatal imaging for predicting postnatal outcome in children with myelomeningocele (Table 5). Biggio et al. ${ }^{5}$ published a study of 33 patients in whom the prenatal US spinal level correlated with the postnatal ambulatory status evaluated at 2 years of age or older (no prenatally observed patients with thoracic lesions were ambulatory at 2 or more years, all patients with L4-sacral lesions were ambulatory at 2 or more years, and $50 \%$ of patients with L1-3 lesions were ambulatory at 2 or more years). Chao et al. ${ }^{9}$ studied the associations of prenatal MRI findings with postnatal outcomes in 36 children with neural tube defects, finding that the absence of a covering membrane on MRI was associated with postnatal scoliosis (36\% vs $0 \%$ with membrane present) and with high-risk bladder dysfunction $(71 \%$ vs $36 \%$; both $\mathrm{p}<0.05$ ). These authors also observed that a higher lesion level, a larger segment span, and an interpediculate distance $>10 \mathrm{~mm}$ were associated with full-time wheelchair use (all three: $p<0.05$ ). Van Der Vossen et al..$^{22}$ reported that a higher prenatal US lesion level correlated with higher odds of death by 5 years of age, but they did not find correlates with motor functioning at 5 years of age. If prenatal imaging is indeed accurate at predicting postnatal outcome, this information could prove valuable in prenatal counseling as well as in predicting postnatal needs in light of the predicted prenatal deficit.

\section{Study Limitations}

This study has several limitations. The generalizability of our results is limited by the fact that our analysis only includes data from a single center. Furthermore, the sample size is relatively small. We only analyzed data on postnatal myelomeningocele closure; therefore, our results are potentially not applicable to patients who undergo prenatal closure. We only reported physical therapy evaluation at the postnatal, postclosure time point, meaning that the postnatal, preclosure motor deficit was not formally assessed by a PT for all infants; it would be ideal to have both preclosure and postclosure postnatal PT assessments, especially in order to evaluate any difference in the motor deficit level pre- and postoperatively. The retrospective nature of this analysis limits a more standardized approach to imaging modalities/techniques, imaging analysis methods, and timing of the prenatal imaging and postnatal PT evaluation. Images were only reviewed by the initial radiologist except in instances in which there was ambiguity in the initial radiology report. The PT evaluations were not performed by the same therapist, which could lead to interobserver variability in how the motor deficit evaluations were performed. Despite these limitations, we believe these data provide valuable insight into the predictive ability of prenatal US and MRI with regard to postnatal motor deficits in infants with myelomeningocele.

\section{Conclusions}

We present data correlating prenatal US and MRI spinal levels with postnatal motor deficits in children with myelomeningocele repaired postnatally. These modalities were equally effective at predicting the postnatal motor

TABLE 4. Imaging modality comparison with postnatal motor deficit

\begin{tabular}{lccc}
\hline \multicolumn{1}{c}{ Variable } & Prenatal MRI & Prenatal US & $p$ Value \\
\hline Agreement w/in 1 level of postnatal PT evaluation & $20 / 34(58.8 \%)$ & $22 / 34(64.7 \%)$ & 0.613 \\
\hline Agreement w/in 2 levels of postnatal PT evaluation & $27 / 34(79.4 \%)$ & $29 / 34(85.3 \%)$ & 0.527 \\
\hline K statistic* & 0.37 & 0.40 & - \\
\hline Mean level difference vs postnatal PT motor level $( \pm$ SD) & $1.17 \pm 1.11$ & $1.12 \pm 1.16$ & 0.86 \\
\hline SD $=$ standard deviation. & & & \\
${ }^{*}$ For comparison of agreement within 1 level. & & &
\end{tabular}


TABLE 5. Summary of prior literature on imaging and postnatal outcome in patients with myelomeningocele

\begin{tabular}{|c|c|c|}
\hline Authors \& Year & Cohort \& Study Type & Findings \\
\hline \multicolumn{3}{|c|}{ Comparing different imaging modalities } \\
\hline Aaronson et al., 2003 & $\begin{array}{l}\text { Myelomeningocele patients w/ prenatal US \& } \\
\text { prenatal MRI w/ postnatal spinal radiographs (70 } \\
\text { images) }\end{array}$ & $\begin{array}{l}79 \% \text { of } 70 \text { prenatal US images correlated w/in } 1 \text { level of postnatal } \\
\text { spinal radiographs }(\kappa=0.60) \& 82 \% \text { of } 38 \text { prenatal MR images } \\
\text { correlated w/in } 1 \text { level of postnatal radiographs }(\kappa=0.63)\end{array}$ \\
\hline Bruner et al., 2004 & $\begin{array}{l}\text { Consecutive cases of spina bifida repaired in utero } \\
\text { w/ comparison of prenatal US w/ postnatal radi- } \\
\text { ography ( } 171 \text { cases) }\end{array}$ & $\begin{array}{l}\text { US agreed perfectly w/ postnatal radiographs in } 26 \% \text { of cases, } \\
66 \% \text { agreed w/in } 1 \text { level, \& } 80 \% \text { agreed w/in } 2 \text { levels }\end{array}$ \\
\hline Carreras et al., 2016 & $\begin{array}{l}\text { Prenatal US \& postnatal neurological examination in } \\
\text { infants w/ myelomeningocele (18 infants) }\end{array}$ & $\begin{array}{l}\text { Agreement btwn prenatal US \& postnatal segmental levels on } \\
\text { examination was } 91.7 \% \text { for } r t \operatorname{limb}(\kappa=0.80) \& 88.9 \% \text { for It } \\
\operatorname{limb}(\kappa=0.73)\end{array}$ \\
\hline Griffiths et al., 2006 & $\begin{array}{l}\text { Patients w/ fetal US \& MRI w/ general spinal defor- } \\
\text { mity (50 fetuses) }\end{array}$ & $\begin{array}{l}\text { In } 40(80 \%) \text { of } 50 \text { fetuses, MRI \& US imaging were in complete } \\
\text { agreement regarding level \& pathology of deformity }\end{array}$ \\
\hline \multicolumn{3}{|c|}{ Prenatal imaging predicting postnatal outcome } \\
\hline Biggio et al., 2001 & $\begin{array}{l}\text { Patients w/ prenatal US \& postnatal ambulatory } \\
\text { status evaluated at } \geq 2 \text { yrs of age ( } 33 \text { patients) }\end{array}$ & $\begin{array}{l}\text { Prenatal US spinal level correlated w/ postnatal ambulatory sta- } \\
\text { tus (no prenatally observed patients w/ thoracic lesions were } \\
\text { ambulatory at } \geq 2 \mathrm{yrs} \text {, all patients w/ L4-sacral lesions were } \\
\text { ambulatory at } \geq 2 \mathrm{yrs}, \& 50 \% \text { of patients w/ L1-3 lesions were } \\
\text { ambulatory at } \geq 2 \mathrm{yrs} \text { ) }\end{array}$ \\
\hline Chao et al., 2011 & $\begin{array}{l}\text { Prenatal MRI findings associated w/ postnatal } \\
\text { outcomes in children w/ neural tube defects ( } 36 \\
\text { patients) }\end{array}$ & $\begin{array}{l}\text { Higher prenatal lesion level, larger segment span, \& interpedicu- } \\
\text { late distance }>10 \mathrm{~mm} \text { were associated w/ full-time wheelchair } \\
\text { use (all } 3: p<0.05 \text { ) }\end{array}$ \\
\hline Van Der Vossen et al., 2009 & $\begin{array}{l}\text { Prenatal US examinations of live-born children who } \\
\text { were prenatally diagnosed w/ spina bifida ( } 41 \\
\text { cases) }\end{array}$ & $\begin{array}{l}\text { Higher prenatal US lesion level correlated w/ higher odds of } \\
\text { death by } 5 \text { yrs of age, but no correlation w/ motor functioning } \\
\text { at } 5 \text { yrs of age }\end{array}$ \\
\hline
\end{tabular}

deficit level and were generally within one level of the postnatally observed motor deficit. These data may be helpful in prenatal prognostication.

\section{Acknowledgments}

We thank Lynette Holman for coordination of the study IRB and Kristin Kraus for editorial assistance.

\section{References}

1. Aaronson OS, Hernanz-Schulman M, Bruner JP, Reed GW, Tulipan NB: Myelomeningocele: prenatal evaluation-comparison between transabdominal US and MR imaging. Radiology 227:839-843, 2003

2. Adzick NS, Thom EA, Spong CY, Brock JW III, Burrows PK, Johnson MP, et al: A randomized trial of prenatal versus postnatal repair of myelomeningocele. N Engl J Med 364:993-1004, 2011

3. Appasamy M, Roberts D, Pilling D, Buxton N: Antenatal ultrasound and magnetic resonance imaging in localizing the level of lesion in spina bifida and correlation with postnatal outcome. Ultrasound Obstet Gynecol 27:530-536, 2006

4. Behrendt N, Zaretsky MV, West NA, Galan HL, Crombleholme TM, Meyers ML: Ultrasound versus MRI: is there a difference in measurements of the fetal lateral ventricles? J Matern Fetal Neonatal Med 30:298-301, 2017

5. Biggio JR Jr, Owen J, Wenstrom KD, Oakes WJ: Can prenatal ultrasound findings predict ambulatory status in fetuses with open spina bifida? Am J Obstet Gynecol 185:10161020,2001

6. Bruner JP, Tulipan N, Dabrowiak ME, Luker KS, Walters K, Burns P, et al: Upper level of the spina bifida defect: how good are we? Ultrasound Obstet Gynecol 24:612-617, 2004
7. Cameron MH, Monroe L: Physical Rehabilitation: Evidence-Based Examination, Evaluation, and Intervention. St. Louis: Saunders, 2007

8. Carreras E, Maroto A, Illescas T, Meléndez M, Arévalo S, Peiró JL, et al: Prenatal ultrasound evaluation of segmental level of neurological lesion in fetuses with myelomeningocele: development of a new technique. Ultrasound Obstet Gynecol 47:162-167, 2016

9. Chao TT, Dashe JS, Adams RC, Keefover-Hicks A, McIntire DD, Twickler DM: Fetal spine findings on MRI and associated outcomes in children with open neural tube defects. AJR Am J Roentgenol 197:W956-W961, 2011

10. Copp AJ, Adzick NS, Chitty LS, Fletcher JM, Holmbeck GN, Shaw GM: Spina bifida. Nat Rev Dis Primers 1:15007, 2015

11. Frontera WR, Silver JK, Rizzo TD Jr: Essentials of Physical Medicine and Rehabilitation. Philadelphia: Saunders, 2014

12. Garel C, Alberti C: Coronal measurement of the fetal lateral ventricles: comparison between ultrasonography and magnetic resonance imaging. Ultrasound Obstet Gynecol 27:23-27, 2006

13. Griffiths PD, Widjaja E, Paley MN, Whitby EH: Imaging the fetal spine using in utero MR: diagnostic accuracy and impact on management. Pediatr Radiol 36:927-933, 2006

14. Kshettry VR, Kelly ML, Rosenbaum BP, Seicean A, Hwang L, Weil RJ: Myelomeningocele: surgical trends and predictors of outcome in the United States, 1988-2010. J Neurosurg Pediatr 13:666-678, 2014

15. Liptak GS, Dosa NP: Myelomeningocele. Pediatr Rev 31:443-450, 2010

16. McDonald CM, Jaffe KM, Mosca VS, Shurtleff DB: Ambulatory outcome of children with myelomeningocele: effect of lower-extremity muscle strength. Dev Med Child Neurol 33:482-490, 1991 
17. McDonald CM, Jaffe KM, Shurtleff DB, Menelaus MB: Modifications to the traditional description of neurosegmental innervation in myelomeningocele. Dev Med Child Neurol 33:473-481, 1991

18. Miller E, Ben-Sira L, Constantini S, Beni-Adani L: Impact of prenatal magnetic resonance imaging on postnatal neurosurgical treatment. J Neurosurg 105 (3 Suppl):203-209, 2006

19. Perlman S, Shashar D, Hoffmann C, Yosef OB, Achiron R, Katorza E: Prenatal diagnosis of fetal ventriculomegaly: agreement between fetal brain ultrasonography and MR imaging. AJNR Am J Neuroradiol 35:1214-1218, 2014

20. Saleem SN, Said AH, Abdel-Raouf M, El-Kattan EA, Zaki MS, Madkour N, et al: Fetal MRI in the evaluation of fetuses referred for sonographically suspected neural tube defects (NTDs): impact on diagnosis and management decision. Neuroradiology 51:761-772, 2009

21. Santos XM, Papanna R, Johnson A, Cass DL, Olutoye OO, Moise KJ Jr, et al: The use of combined ultrasound and magnetic resonance imaging in the detection of fetal anomalies. Prenat Diagn 30:402-407, 2010

22. Van Der Vossen S, Pistorius LR, Mulder EJ, Platenkamp M, Stoutenbeek P, Visser GH, et al: Role of prenatal ultrasound in predicting survival and mental and motor functioning in children with spina bifida. Ultrasound Obstet Gynecol 34:253-258, 2009
23. Wright J: Neurosegmental level and functional status, in Sarwark J, Lubicky J (eds): Caring for the Child with Spina Bifida. Rosemont, IL: American Academy of Orthopaedic Surgeons, 2001, pp 67-78

\section{Disclosures}

The authors report no conflict of interest concerning the materials or methods used in this study or the findings specified in this paper.

\section{Author Contributions}

Conception and design: Bollo, Ho. Acquisition of data: Sherrod, Ho. Analysis and interpretation of data: Sherrod, Ho. Drafting the article: Bollo, Sherrod, Ho, Hedlund. Critically revising the article: Bollo, Sherrod, Ho, Kennedy, Ostrander. Reviewed submitted version of manuscript: Bollo, Sherrod, Ho. Approved the final version of the manuscript on behalf of all authors: Bollo.

\section{Correspondence}

Robert J. Bollo: Primary Children's Hospital, Salt Lake City, UT. neuropub@hsc.utah.edu. 